Finfidt ju verfanffen, fo wie strigmul unt practifbes

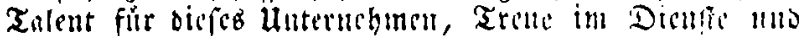

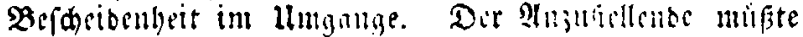
(id) alf $3=4$ Salyr verpfliden, dom Finbufinbaber nber

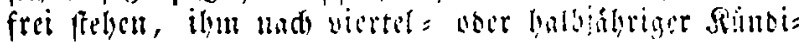

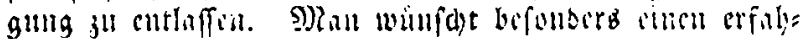
remen giputgefirgelgulfiu.

2huf franfirt eqligefand werbende 2Tufragen crtbcilt nifere Padyridt

$$
\text { Dr. IB i ufler, }
$$

Dbferwatur all der Stermuate ju Salle.

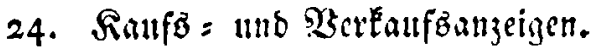

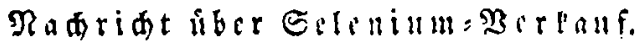

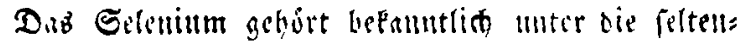

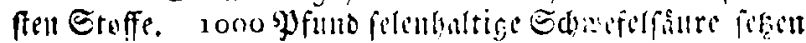

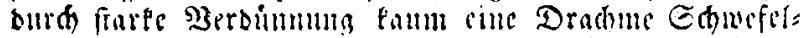

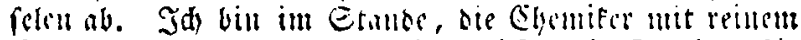
Erlen jut verfurgell, and erbiert mid, ofi Dradsme fite

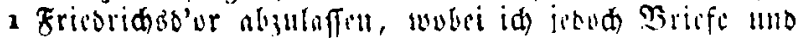

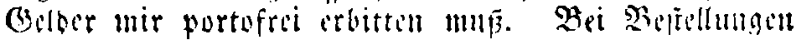

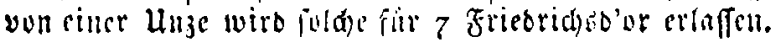

Erfurt in Sinntiat 1825.

Di. S. B. Trummsoorff.

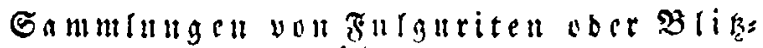

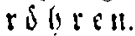

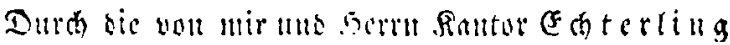

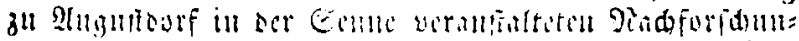
gen and stuggralthing

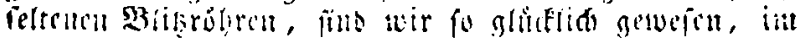

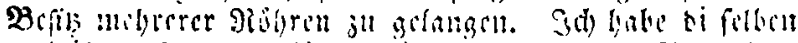

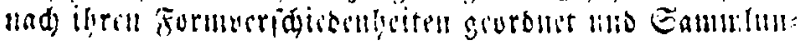




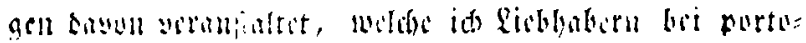

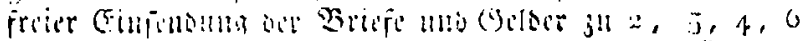

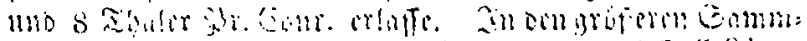

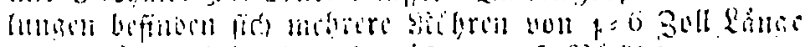

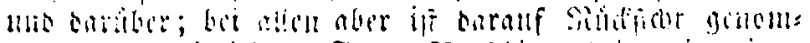

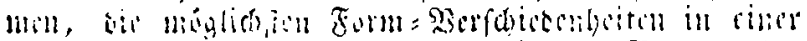

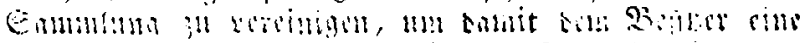

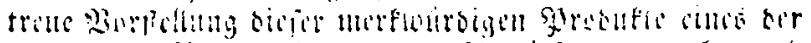

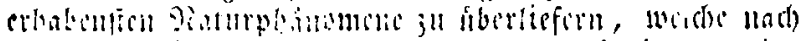

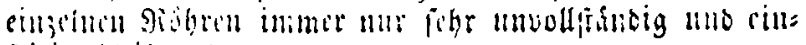
pirrig briben fanti.

Enljuficm in Sibunar 1825.

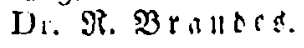

Contex adstringens.

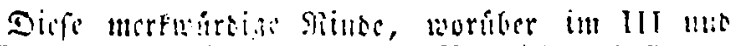

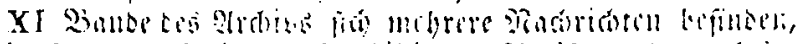

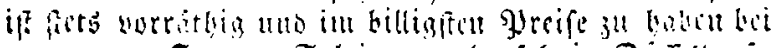

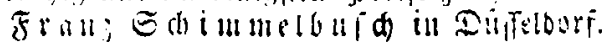

Arater= uno itberijde Dele un narkoti= id)e exteate.

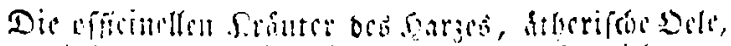

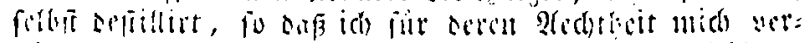

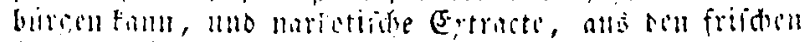

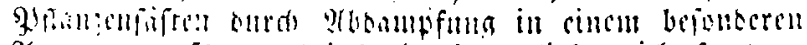

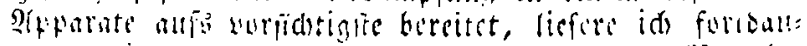

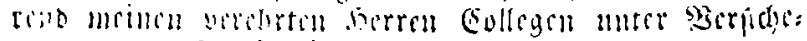

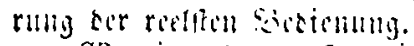

פgermigurube an Searj im Srcumler 1824. For té s, sputhiter.

Sx ล

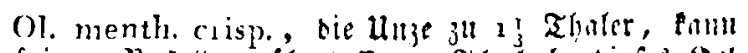

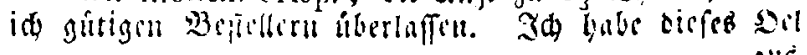


aus einem betriddtiden Burrathe von Rraut felb/t bes fillitt.

Niegrim im Sadrbornften.

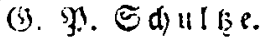

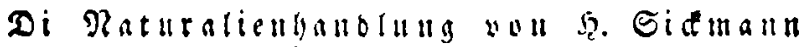

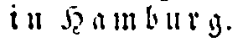

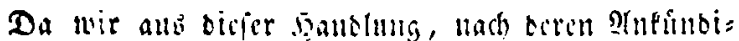

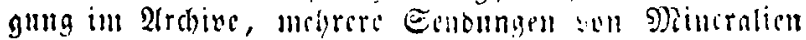

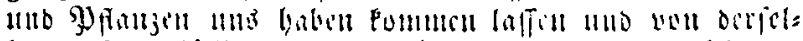

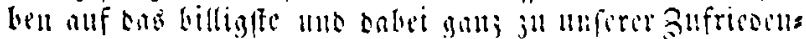

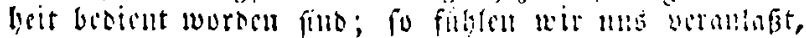

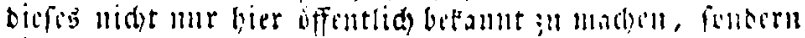

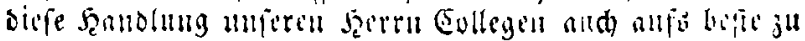
elupfeglen.

$\mathfrak{A}$ d of $f$,

Meticiualuffefor in Diclefilb.

(5. $2(j$ di) off ill Serfurt.

\section{7. 23itherangeigen.}

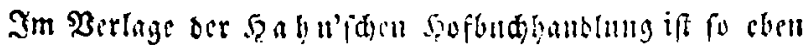
crịcicusn:

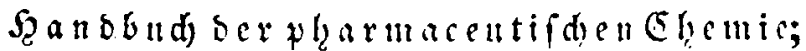

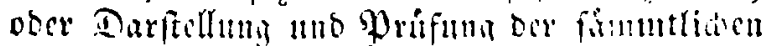
d)emifd = plyamacentifichen Po a yarate; le: fonbera zum practifien Sichaudic fir Whufici,

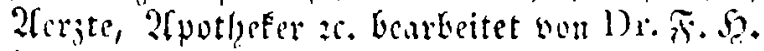

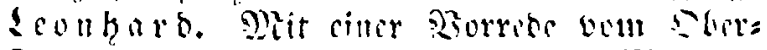

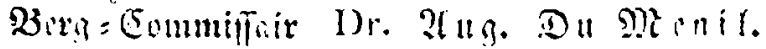
gr. 8. 1825 .

I sitbl.

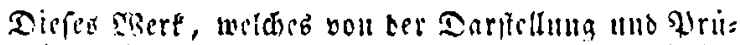

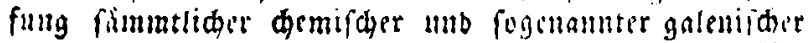
Shis 